Published in final edited form as:

Schizophr Res. 2014 March ; 153(0): 184-188. doi:10.1016/j.schres.2014.01.017.

\title{
Tardive Dyskinesia in Relation to Estimated Dopamine D2 Receptor Occupancy in Patients with Schizophrenia: Analysis of the CATIE data
}

\author{
Kazunari Yoshida, MD ${ }^{\mathrm{a}}$, Robert R. Bies, PharmD, PhD ${ }^{\mathrm{b}, \mathrm{c}, \mathrm{d}}$, Takefumi Suzuki, MD, PhD ${ }^{\mathrm{a}, \mathrm{e}}$, \\ Gary Remington, MD, PhD ${ }^{f, g}$, Bruce G. Pollock, MD, PhD ${ }^{b, g}$, Yuya Mizuno, MD ${ }^{a}$, Masaru \\ Mimura, MD, PhDa ${ }^{a}$, and Hiroyuki Uchida, MD, PhD ${ }^{a, b}$ \\ a Department of Neuropsychiatry, Keio University School of Medicine, Tokyo, Japan \\ b Geriatric Mental Health Program, Centre for Addiction and Mental Health, Toronto, ON, Canada \\ c Division of Clinical Pharmacology, Indiana University School of Medicine, Indianapolis, IN, USA \\ d Indiana Clinical and Translational Sciences Institute, Indianapolis, IN, USA \\ e Department of Psychiatry, Inokashira Hospital, Tokyo, Japan \\ f Schizophrenia Division/Complex Mental Illness Program, Centre for Addiction and Mental \\ Health, Toronto, ON, Canada
}

\author{
(c) 2014 Published by Elsevier B.V. \\ Corresponding author: Hiroyuki Uchida, MD, PhD Department of Neuropsychiatry, Keio University School of Medicine 35, \\ Shinanomachi, Shinjuku-ku, Tokyo, 160-8582, Japan. hiroyuki.uchida.hu@ gmail.com Phone: +81.3.5363.3829 Fax: \\ +81.3 .5379 .0187 . \\ Publisher's Disclaimer: This is a PDF file of an unedited manuscript that has been accepted for publication. As a service to our \\ customers we are providing this early version of the manuscript. The manuscript will undergo copyediting, typesetting, and review of \\ the resulting proof before it is published in its final citable form. Please note that during the production process errors may be \\ discovered which could affect the content, and all legal disclaimers that apply to the journal pertain. \\ Previous presentation: \\ None \\ Contributors \\ All authors contributed to and have approved the design and the protocol of the study and the literature searches. Drs. Yoshida, Bies, \\ and Uchida analyzed the data. Drs. Yoshida and Uchida wrote the first draft of the manuscript, and all authors contributed to and have \\ approved the final manuscript. \\ Conflicts of interest \\ Dr. Yoshida has received speaker's honoraria from Meiji within the past two years. Dr. Bies has received NIH, CAMH, Lilly, Merck \\ and Indiana University based grant funding. Dr. Suzuki has received manuscript fees or speaker's honoraria from Dainippon \\ Sumitomo, Eli Lilly, Astellas, Novartis, Otsuka, Elsevier Japan, Wiley Japan and Meiji Seika within the past two years. Dr. \\ Remington has received research support from the Canadian Diabetes Association, the Canadian Institutes of Health Research, \\ Medicure, Neurocrine Biosciences, Novartis Canada, Research Hospital Fund-Canada Foundation for Innovation, and the \\ Schizophrenia Society of Ontario and has served as a consultant or speaker for Novartis, Laboratorios Farmacéuticos Rovi, \\ Synchroneuron, and Roche within the past three years. Dr. Pollock receives research support from the National Institute of Health, \\ Canadian Institutes of Health Research, American Psychiatric Association, and the Foundation of the Centre for Addiction and Mental \\ Health. Within the past five years he has been a member of the advisory board of Lundbeck Canada (final meeting was May 2009) and \\ Forest Laboratories (final meeting was March 2008). Dr. Pollock has served one time as a consultant for Wyeth (October 2008) and \\ Takeda (July 2007). He was also a faculty member of the Lundbeck International Neuroscience Foundation (LINF) (final meeting was \\ April 2010). Dr. Mizuno has received manuscript fees or speaker's honoraria from Dainippon Sumitomo Pharma, Eli Lilly and Wiley \\ Japan within the past two years. Dr. Mimura has received grants, or consultant fees from Eisai, Astellas Pharma, GlaxoSmithKline and \\ Meiji, and received speaker's honoraria from Astellas Pharma, Dainippon Sumitomo Pharma, Eli Lilly, GlaxoSmithKline, Janssen \\ Pharmaceutical, Meiji, Otsuka Pharmaceutical, Pfizer, and Yoshitomiyakuhin within the past two years. Dr. Uchida has received \\ grants from Pfizer, Astellas Pharmaceutical, Eisai, Otsuka Pharmaceutical, GlaxoSmithKline, Shionogi, and Dainippon-Sumitomo \\ Pharma, Eli Lilly, Mochida Pharmaceutical, Meiji-Seika Pharma, Janssen Pharmaceutical, and Yoshitomi Yakuhin and speaker's \\ honoraria from Otsuka Pharmaceutical, Novartis Pharma, Eli Lilly, Shionogi, GlaxoSmithKline, Yoshitomi Yakuhin, Dainippon- \\ Sumitomo Pharma, Meiji-Seika Pharma, and Janssen Pharmaceutical within the past two years.
}


g Department of Psychiatry, University of Toronto, Toronto, ON, Canada

\section{Abstract}

Objective-The objective of this study was to evaluate the relationship between antipsychoticinduced tardive dyskinesia (TD) and estimated dopamine D2 receptor occupancy levels in patients with schizophrenia, using the dataset from the Clinical Antipsychotic Trials in Intervention Effectiveness (CATIE).

Methods-The dataset from 218 subjects (risperidone, $\mathrm{N}=78$; olanzapine, $\mathrm{N}=100$; ziprasidone, $\mathrm{N}=40$ ) who presented with a score of zero on the Abnormal Involuntary Movement Scale (AIMS) at baseline in Phase 1 of the CATIE study, and remained for $\ 6$ months, was used. Peak and trough dopamine D2 receptor occupancy levels on the day of the AIMS assessment at the endpoint were estimated from plasma antipsychotic concentrations, using population pharmacokinetic analysis and our D2 prediction model. The estimated dopamine D2 receptor occupancy levels were compared between patients who presented an AIMS score of $\geq 2$ at endpoint and those with a score of zero, using the Mann-Whitney U test.

Results-Estimated dopamine D2 receptor occupancy levels at trough were significantly higher in subjects who developed involuntary movements $(\mathrm{N}=23)$ than those who did not $(\mathrm{N}=195)$ $(71.7 \pm 14.4 \%$ vs. $64.3 \pm 19.3 \%, \mathrm{p}<0.05)$ while no significant difference was found in the estimated peak D2 receptor occupancy between them $(75.4 \pm 8.7 \%$ vs. $72.1 \pm 9.9 \%, \mathrm{p}=0.07)$. When the analyses were separately conducted for the three drugs, there were no significant differences in estimated peak or trough D2 occupancy although the values were consistently numerically higher among those developing involuntary movements.

Conclusion-Greater dopamine D2 receptor blockade with antipsychotics at trough might increase the risk of tardive involuntary movements although this finding needs to be replicated in larger trials.

\section{Keywords}

abnormal involuntary movement; antipsychotics; CATIE; dopamine D2 receptor; schizophrenia; tardive dyskinesia

\section{Introduction}

Second-generation antipsychotics (SGAs) have come to play an important role in the treatment of schizophrenia. While lines of evidence suggest a diminished liability to extrapyramidal symptoms (EPS) of SGAs compared to conventional antipsychotics (Tollefson et al., 1997; Haro et al., 2003a; Haro et al., 2003b; Correll et al., 2004; Dossenbach et al., 2004; Tenback et al., 2005), it should be emphasized that the former agents still continue to carry a risk for tardive dyskinesia (TD) (Kapur et al., 1995; Woods et al., 2010). Findings arising from conventional antipsychotics indicated a prevalence of approximately $20-25 \%$ in the face of long-term treatment with these antipsychotics (Blanchet, 2003), with identified clinical risk factors including older age, female gender, and the duration of antipsychotic treatment (Kapur et al., 1995; Egan et al., 1997; Miller et al., 2005; Remington, 2007; Soares-Weiser and Fernandez, 2007; Tenback et al., 2009; Tenback and van Harten, 2011).

To this last point, theories regarding the pathophysiology of TD have implicated changes in the dopaminergic system, including supersensitivity of dopamine D2 receptors (Egan et al., 1997; Margolese et al., 2005). Recent preclinical evidence has suggested that higher, sustained dopamine D2 occupancy may be linked to an increased risk of TD, with evidence 
that continuous, but not intermittent, exposure to olanzapine is associated with an increased risk of vacuous chewing movements (VCMs), a model for TD, in rats (Turrone et al., 2005). Whether differences reflect the episodic troughs with intermittent treatment or overall differences in total antipsychotic exposure is not entirely clear. For example, reports have also identified higher antipsychotic doses as a risk factor in TD (Chakos et al., 1996; Oosthuizen et al., 2003).

Better understanding the relationship between D2 occupancy (i.e. levels), as well as patterns of D2 occupancy (i.e. peaks and troughs), and risk of TD could advance our understanding of TD and its underlying pathophysiology considerably. Neuroimaging has afforded us the opportunity to examine antipsychotic-related D2 binding in vivo, but practically speaking it is better positioned to provide cross-sectional rather than longitudinal data. However, we have developed a model in which the dopamine D2 receptor occupancy of antipsychotics, including risperidone, olanzapine, and ziprasidone, can be reliably estimated from plasma concentrations (Uchida et al., 2011b). In addition, recent advances in nonlinear, mixedeffects population pharmacokinetic (PPK) methods have made it possible to estimate individual pharmacokinetic parameters for antipsychotics, including peak and trough plasma concentrations, using two or more sparsely collected blood samples (Bigos et al., 2006). By combining these models, the dopamine D2 receptor occupancy levels at any given point in time can be reliably estimated using the measurement of antipsychotic plasma concentrations at two separate random time points (Uchida et al., 2009b).

To elucidate the relationship between TD and estimated peak and trough antipsychoticrelated dopamine D2 receptor blockade, the Clinical Antipsychotic Trials in Intervention Effectiveness (CATIE) (Stroup et al., 2003) provides an ideal dataset given its unprecedented large sample size and availability of plasma antipsychotic concentrations. In fact, PPK models have already been developed for risperidone, olanzapine, and ziprasidone (Bigos et al., 2008; Feng et al., 2008; Wessels et al., 2011). The objective of this report was, however, to evaluate the relationship between estimated dopamine D2 receptor occupancy with risperidone, olanzapine, and ziprasidone and TD.

\section{Materials and methods}

\subsection{Study design}

The CATIE was funded by the National Institute of Mental Health to compare the effectiveness of SGAs in schizophrenia, and it has been detailed elsewhere (Stroup et al., 2003). Briefly, it was performed between January 2001 and December 2004 at 57 clinical sites in the United States. One thousand four hundred and ninety-three patients between ages 18 and 65 and with a diagnosis of schizophrenia based on the Structured Clinical Interview of the DSM-IV, participated in the trial. Patients were initially randomized to risperidone ( $1.5-6.0 \mathrm{mg} /$ day), olanzapine ( $7.5-30 \mathrm{mg} / \mathrm{day})$, ziprasidone (40-160 $\mathrm{mg} /$ day), quetiapine (200-800 mg/day), or perphenazine (8-32 mg/day) under double-blind conditions, and received treatments for up to 18 months or until treatment was discontinued for any reason (Phase 1).

Data used in this analysis were derived from the subjects who were receiving risperidone, olanzapine, or ziprasidone, presented with a total score of zero on the Abnormal Involuntary Movement Scale (AIMS) at baseline in Phase 1 of CATIE, provided plasma samples for the assessment of antipsychotic concentrations, and participated in the study for six months or longer. Only subjects on these three drugs were included since prediction models of dopamine D2 receptor occupancy from plasma drug concentrations are available for only these drugs amongst those available through CATIE (Bigos et al., 2008; Feng et al., 2008; 
Wessels et al., 2011). All participants gave written informed consent to participate in the protocols approved by the local institutional review boards.

\subsection{Population pharmacokinetic analysis}

Subjects in CATIE provided plasma samples for the measurement of concentrations of risperidone plus 9-hydroxyrisperidone (active moiety), olanzapine, or ziprasidone at more than one time point. Using these samples, plasma antipsychotic concentrations at peak and trough that corresponded to the dose given at endpoint of Phase 1 were calculated for each individual, using the established PPK models and extracting the Empirical Bayes Estimates for the pharmacokinetic parameters for each of these individuals (Sheiner et al., 1977; Beal and Sheiner, 1992). The precision and reliability of this estimation has recently been confirmed in our PPK study (Uchida et al., 2012). The nonlinear mixed-effect models for risperidone, olanzapine, and ziprasidone were previously established using the CATIE data (Bigos et al., 2008; Feng et al., 2008; Wessels et al., 2011). These original studies, used to establish the PPK models, comprised 1236 risperidone plus 9-hydroxyrisperidone concentrations from 490 subjects, 1527 olanzapine concentrations from 523 subjects, and 568 ziprasidone concentrations from 233 subjects, respectively. All three compounds were adequately described by using a one-compartment linear model with first order absorption. In addition, the risperidone model comprised: exponentiated inter-individual variability on each pharmacokinetic parameter; a tri-modal mixture distribution on risperidone clearance (a reflection of the fact that CYP 2D6 genotype was not available for patients on this drug); and an age effect on the clearance of the 9-hydroxyrisperidone metabolite. The olanzapine model incorporated age, sex and race effects on clearance of the drug. PPK analysis has been utilized to characterize pharmacokinetic profiles of medications such as antibiotic and anticancer agents (Marsot et al., 2012; Kontny et al., 2013).

\subsection{Estimation of dopamine D2 receptor occupancy}

Utilizing the estimated plasma concentrations of antipsychotics (peak and trough) at endpoint in Phase 1 of CATIE, corresponding dopamine D2 receptor occupancy levels were estimated using the model that we developed (Uchida et al., 2011b). Briefly, dopamine D2 receptor occupancy levels were calculated by incorporating the estimated plasma concentration of risperidone active moiety, olanzapine, or ziprasidone into the following one-site binding model: occupancy $(\%)=a \mathrm{x}$ [plasma level $/$ (plasma level + ED50)], where $a$ is the maximum receptor occupancy attributable to the antipsychotic drug and ED50 is the estimated plasma concentration of the antipsychotic drug associated with 50\% receptor occupancy, which was obtained in the systematic review and pooled analysis (Risperidone active moiety: $a=88.0 \%, \mathrm{ED}_{50}=4.9 \mathrm{ng} / \mathrm{ml}$; olanzapine: $a=90.7 \%, \mathrm{ED}_{50}=7.1 \mathrm{ng} / \mathrm{ml}$; ziprasidone: $a=88.2 \%, \mathrm{ED}_{50}=32.9 \mathrm{ng} / \mathrm{ml}$ ) (Uchida et al., 2011b). This estimation method was previously developed for haloperidol by Fitzgerald et al. (Fitzgerald et al., 2000).

\subsection{Statistical analysis}

Statistical analyses were performed by using the SPSS Version 21.0 (IBM, New York). Subjects were divided into two groups based on the presence of TD. The estimated peak and trough dopamine D2 receptor occupancy levels were compared between patients who presented with an AIMS score of $\geq 2$ at endpoint and those whose AIMS score remained at zero using the Mann-Whitney U test, respectively. Likewise, oral doses were compared between those two groups in the total sample and subgroups of patients receiving those three drugs, respectively, using the Mann-Whitney U test. For this analysis, oral doses (mg/day) were converted to Defined Daily Dose (DDD) Unit. This unit of measurement used for standardizing antipsychotic doses was developed by the World Health Organization Collaborating Centre for Drug Statistics Methodology system of Defined Daily Doses 
(WHO. Collaborating Centre for Drug Statistics Methodology, 2013). The DDD unit is the assumed average dose ( $\mathrm{mg}$ ) per day for a drug used for its main indication in adults (e.g. schizophrenia for antipsychotics): 5 for risperidone (oral), 10 for olanzapine (oral), and 80 for ziprasidone. In addition, a binary logistic regression model was used to examine the effects of estimated dopamine D2 receptor occupancy levels, age group (i.e. $<50$ or $\geq 50$ years), sex, antipsychotics, years since the first antipsychotic was prescribed, the duration of study participation and race (i.e. Caucasian, African-American, Native American, or others) on the presence of TD. A p-value of $<0.05$ was considered statistically significant (twotailed).

\section{Results}

\subsection{Subject characteristics}

Two hundred and eighteen subjects were included; demographic and clinical characteristics are summarized in Table 1 . Mean \pm SD daily doses of risperidone, olanzapine, and ziprasidone on the day of AIMS score assessments at endpoint were $4.6 \pm 1.3 \mathrm{mg}, 21.6 \pm 7.5$ $\mathrm{mg}$, and $123.0 \pm 34.3 \mathrm{mg}$, respectively. Mean \pm SD AIMS score at endpoint was 0.39 \pm 1.26 .

\subsection{Association between estimated D2 receptor occupancy and TD}

Estimated dopamine D2 receptor occupancy levels at trough were significantly higher in subjects who presented with an AIMS score of $\geq 2$ at endpoint $(\mathrm{N}=23)$ versus those with a score of zero $(\mathrm{N}=195)(71.7 \pm 14.4 \%$ vs. $64.3 \pm 19.3 \%, \mathrm{p}<0.05)$, while no significant difference was found in the estimated peak D2 receptor occupancy between them $(75.4 \pm 8.7 \%$ vs. $72.1 \pm 9.9 \%, \mathrm{p}=0.07)$. When the same analyses were separately conducted for those three individual antipsychotics, there were no significant differences in estimated peak and trough D2 receptor occupancy for any of them between subjects who presented with an AIMS score of $\geq 2$ at endpoint versus those with a score of zero (risperidone, $77.7 \pm 3.8 \%$ $(\mathrm{N}=8)$ vs. $74.6 \pm 6.3 \%(\mathrm{~N}=70)$ at peak and $76.0 \pm 4.5 \%$ vs. $71.0 \pm 8.6 \%$ at trough; olanzapine, $77.8 \pm 6.6 \%(\mathrm{~N}=12)$ vs. $75.0 \pm 8.0 \%(\mathrm{~N}=88)$ at peak and $75.3 \pm 9.1 \%$ vs. $71.9 \pm 10.1 \%$ at trough; ziprasidone, $59.6 \pm 10.7 \%(\mathrm{~N}=3)$ vs. $60.4 \pm 11.0 \%(\mathrm{~N}=37)$ at peak and $45.4 \pm 23.9 \%$ vs. $33.4 \pm 20.0 \%$ at trough, respectively).

The binary logistic regression model revealed that old age, sex, race, years of antipsychotic treatment, the duration of study participation, drug, and estimated dopamine D2 receptor occupancy levels at peak and trough failed to demonstrate any statistically significant effects on the emergence of TD (Table 2).

\subsection{Association between oral dose and TD}

No significant difference was found in the DDD between subjects who presented with an AIMS score of $\geq 2$ at endpoint versus those with score of zero (1.78 \pm 0.86 vs. $1.59 \pm 0.78$, $\mathrm{p}=0.27$ ). Also when the same analyses were separately conducted for each of three individual antipsychotics, there were no significant differences in the DDD between them (risperidone, $0.97 \pm 0.31$ vs. $0.93 \pm 0.27$; olanzapine, $2.43 \pm 0.64$ vs. $2.13 \pm 0.76$; ziprasidone, $1.33 \pm 0.28$ vs. $1.55 \pm 0.43$, respectively).

\section{Discussion}

While the subjects who experienced TD showed significantly higher trough estimated dopamine D2 receptor occupancy levels than those who did not, no statistically significant difference was observed in peak dopamine D2 occupancy between them. However, the association between trough dopamine D2 occupancy and TD was not found in the regression 
analysis. Although findings must be viewed as preliminary, they indicate the relevance of trough $\mathrm{D} 2$ blockade in the emergence of TD.

Animal studies involving antipsychotics have already demonstrated the impact of dosing schedules on abnormal movements (Turrone et al., 2003; Turrone et al., 2005). Turrone et al. examined whether continuous, versus intermittent, infusion of olanzapine affects the development of VCMs differentially in rats. Rats were treated with $7.5 \mathrm{mg} / \mathrm{kg} /$ day of olanzapine via mini-pump or daily subcutaneous injections for eight weeks. Rats that were continuously given olanzapine via mini-pump (mean dopamine D2 occupancy of 51\%) demonstrated significantly greater VCM levels when compared to animals receiving daily subcutaneous injections (94\% and 15\% D2 occupancy at peak and trough, respectively) (Turrone et al., 2005).

Preclinical evidence has also demonstrated that gaps in sustained, higher D2 occupancy may impact antipsychotic response, reflective of possible tolerance. For example, Carey et al. evaluated antipsychotic-suppressed spontaneous motor activity in rats receiving injections of haloperidol twice daily and every other day (Carey and DeVeaugh-Geiss, 1984). In contrast to the every other day group, the twice-daily injection schedule group exhibited recovery of spontaneous motor activity, suggestive of behavioral tolerance. Based on these findings, they suggested that treatment schedule, rather than cumulative drug dosage, plays a role in the development of tolerance to haloperidol as well as long-term side effects such as TD. Antipsychotic treatment with low dopamine D2 blockade at trough may also be beneficial to maintain antipsychotic effects. More recently, Samaha et al. compared the effects of withinday continuous antipsychotic exposure via osmotic mini-pump versus transient treatment (i.e. daily subcutaneous injections of haloperidol at doses achieving equivalent peak striatal D2 receptor occupancy levels) in rats (Samaha et al., 2008). While the latter maintained efficacy, the former (i.e. continuous exposure) lost efficacy in the suppression of amphetamine-induced locomotion and conditioned avoidance, animal models of antipsychotic-like effects. In addition, changes in the density of striatal D2 receptors and D2 receptors in a high-affinity state for dopamine (D2 $\left.{ }^{\mathrm{High}}\right)$ were measured. Once more, differences were found. The continuous group demonstrated significantly elevated D2 receptor binding versus the transient group, and while, both also showed elevated levels of $\mathrm{D} 2^{\text {High }}$ density, the increase was greater in the continuous. Results suggest that antipsychotic effects may be attenuated in the face of continuous antipsychotic treatment/ exposure, linked in turn to increases in density of striatal D2 receptors and D2 receptors in a high-affinity (Samaha et al., 2007; Samaha et al., 2008).

Moving these findings to humans, Remington et al. compared the efficacy of extended, but regular (i.e. alternate day) dosing of antipsychotics to once daily dosing in a double-blind, placebo-controlled trial $(\mathrm{N}=35)$, reporting no increase in the risk of symptom exacerbation, relapse, or re-hospitalization in the former group over six months (Remington et al., 2011). Although dopamine $\mathrm{D}_{2}$ receptor occupancy levels were not measured in this study, it would be reasonable to assume that subjects in the extended dosing group had lower levels of D2 receptor occupancy at trough. Consistent with this notion, Uchida et al. have demonstrated that sustained blockade of dopamine $\mathrm{D}_{2}$ receptor occupancy at $\Varangle 65 \%$ may not be necessary for the maintenance treatment of schizophrenia (Mizuno et al., 2011; Ikai et al., 2012; Moriguchi et al., 2013). In those studies, approximately half of clinically stable patients with schizophrenia did not show dopamine D2 receptor occupancy levels $\geq 65 \%$ at trough, as estimated from plasma antipsychotic concentrations (Mizuno et al., 2011; Ikai et al., 2012; Moriguchi et al., 2013). Taken together, the animal literature provides compelling evidence that alterations in antipsychotic dosing impacting not only overall antipsychotic exposure, but patterns of exposure in terms of peaks and troughs, may impact response across time, as well as side effects. We now have human data indicating that high and sustained D2 
occupancy is not required for the maintenance of antipsychotic response, although this work is in its earliest stages. Thus, it is suggested that extended but regular dosing of antipsychotics could maintain clinical stability while reducing the risk of TD. It must be emphasized that it is premature translating these findings to clinical practice; however, further investigations on this topic are clearly warranted.

Results of our study must be interpreted in light of various limitations. First, only patients treated with risperidone, olanzapine, or ziprasidone were included since both the PPK models (Bigos et al., 2008; Feng et al., 2008; Wessels et al., 2011) and the prediction model of dopamine D2 receptor occupancy from plasma concentrations (Uchida et al., 2011b) are presently available only for these three drugs. Any extrapolation to other antipsychotics must be made with caution. Second, dopamine D2 receptor occupancy was not directly measured with brain imaging techniques but was cross-sectionally calculated with the model we have developed; still, the predictive performance of the model has been shown to be reliable (Uchida et al., 2011b). We did not use evaluate the relationship between plasma antipsychotic concentrations and TD for the following reason. Therapeutic and side effects of antipsychotics have been demonstrated to be closely linked to dopamine D2 receptor occupancy (Kapur et al., 1995; Kapur et al., 2000). The relationships between plasma drug concentration and its dopamine D2 receptor occupancy is not linear, but they fit a one site occupancy model (hyperbole saturation equation) Therefore, dopamine D2 occupancy levels reaches a plateau beyond a certain drug concentration, which makes it difficult to statistically examine the relationship between plasma antipsychotic concentrations and their clinical effects. Third, the time frame of six or more months may be short, raising the possibility of false-negative cases in the long run. Finally, our study showed the significant relationship between dopamine D2 occupancy at trough and TD using the Mann-Whitney U test, which was no longer a case with the binary logistic regression model. As such, caution is necessary although some of the negative findings that we observed in the present study may be derived from the small sample size.

In conclusion, the degree of dopamine D2 receptor blockade with antipsychotics at trough might be associated with the risk for TD although this finding needs to be replicated in larger trials. These findings align with a growing body of evidence suggest that we should examine more closely both dose and dosing intervals in the context of longer term antipsychotic maintenance treatment. While D2 blockade appears critical to antipsychotic efficacy (Kapur and Rmington, 2001; Kapur and Mamo, 2003), current evidence does not support the position that high and continuous D2 occupancy is required to sustain response. Indeed, this strategy may both compromise efficacy as well as increase risk of certain side effects. Indeed, this strategy may both compromise efficacy as well as increase risk of certain side effects, which is critically important given that TD still remains a relevant clinical issue even in the era of SGA predominance. The implication of these findings argues strongly for further research that can shed light on these important issues due to some limitations of current study.

\section{Acknowledgments}

Data used in the preparation of this article were obtained from the limited access datasets distributed from the NIHsupported "Clinical Antipsychotic Trials of Intervention Effectiveness in Schizophrenia" (CATIE-Sz). This is a multisite, clinical trial of persons with schizophrenia, comparing the effectiveness of randomly assigned medication treatment. The study was supported by NIMH Contract \# N01MH90001 to the University of North Carolina at Chapel Hill. The ClinicalTrials.gov identifier is NCT00014001. The version of the dataset used was 1.0. This study was also supported by grant R01MH064173 from the National Institute of Mental Health and was ancillary to the Clinical Antipsychotic Trials of Intervention Effectiveness, N01MH90001, from the National Institute of Mental Health. This manuscript reflects the views of the authors and may not reflect the opinions or views of the CATIESz Study Investigators or the NIH. No funding was provided for the present analysis. 
Role of funding source

None

\section{References}

Beal, B.; Sheiner, L. NONMEM user's guide, part I. University of California; San Francisco: 1992.

Bigos KL, Bies RR, Pollock BG. Population pharmacokinetics in geriatric psychiatry. Am. J. Geriatric. Psychiatry. 2006; 14(12):993-1003.

Bigos KL, Pollock BG, Coley KC, Miller DD, Marder SR, Aravagiri M, Kirshner MA, Schneider LS, Bies RR. Sex, race, and smoking impact olanzapine exposure. J. Clin. Pharmacol. 2008; 48(2):157165. [PubMed: 18199892]

Blanchet PJ. Antipsychotic drug-induced movement disorders. Can. J. Neurol. Sci. 30 Suppl. 2003; 1:S101-107.

Carey RJ, DeVeaugh-Geiss J. Treatment schedule as a determinant of the development of tolerance to haloperidol. Psychopharmacology (Berl). 1984; 82(3):164-167. [PubMed: 6425895]

Chakos MH, Alvir JM, Woerner MG, Koreen A, Geisler S, Mayerhoff D, Sobel S, Kane JM, Borenstein M, Lieberman JA. Incidence and correlates of tardive dyskinesia in first episode of schizophrenia. Arch. Gen. Psychiatry. 1996; 53(4):313-319. [PubMed: 8634009]

Correll CU, Leucht S, Kane JM. Lower risk for tardive dyskinesia associated with second-generation antipsychotics: a systematic review of 1-year studies. Am. J. Psychiatry. 2004; 161(3):414-425. [PubMed: 14992963]

Dossenbach M, Erol A, el Mahfoud Kessaci M, Shaheen MO, Sunbol MM, Boland J, Hodge A, O'Halloran RA, Bitter I. Effectiveness of antipsychotic treatments for schizophrenia: interim 6month analysis from a prospective observational study (IC-SOHO) comparing olanzapine, quetiapine, risperidone, and haloperidol. J. Clin. Psychiatry. 2004; 65(3):312-321. [PubMed: 15096069]

Egan MF, Apud J, Wyatt RJ. Treatment of tardive dyskinesia. Schizophr. Bull. 1997; 23(4):583-609. [PubMed: 9365997]

Feng Y, Pollock BG, Coley K, Marder S, Miller D, Kirshner M, Aravagiri M, Schneider L, Bies RR. Population pharmacokinetic analysis for risperidone using highly sparse sampling measurements from the CATIE study. Br. J. Clin. Pharmacol. 2008; 66(5):629-639. [PubMed: 18771484]

Fitzgerald PB, Kapur S, Remington G, Roy P, Zipursky RB. Predicting haloperidol occupancy of central dopamine D2 receptors from plasma levels. Psychopharmacol. (Berl). 2000; 149(1):1-5.

Haddad PM, Dursun SM. Neurological complications of psychiatric drugs: clinical features and management. Hum. Psychopharmacol. 23 Suppl. 2008; 1:15-26.

Haro JM, Edgell ET, Frewer P, Alonso J, Jones PB. The European Schizophrenia Outpatient Health Outcomes Study: baseline findings across country and treatment. Acta Psychiatr Scand Suppl. 2003a; 416:7-15. [PubMed: 12755849]

Haro JM, Edgell ET, Jones PB, Alonso J, Gavart S, Gregor KJ, Wright P, Knapp M. The European Schizophrenia Outpatient Health Outcomes (SOHO) study: rationale, methods and recruitment. Acta psychiatrica Scandinavica. 2003b; 107(3):222-232. [PubMed: 12580830]

Ikai S, Remington G, Suzuki T, Takeuchi H, Tsuboi T, Den R, Hirano J, Tsunoda K, Nishimoto M, Watanabe K, Mimura M, Mamo D, Uchida H. A cross-sectional study of plasma risperidone levels with risperidone long-acting injectable: implications for dopamine D2 receptor occupancy during maintenance treatment in schizophrenia. J. Clin. Psychiatry. 2012; 73(8):1147-1152. [PubMed: 22967779]

Kane JM, Smith JM. Tardive dyskinesia: prevalence and risk factors, 1959 to 1979. Arch. Gen. Psychiatry. 1982; 39(4):473-481. [PubMed: 6121548]

Kapur S, Mamo D. Half a century of antipsychotics and still a central role for dopamine D2 receptors. Prog. Neuropsychopharmacol. Biol. Psychiatry. 2003; 27(7):1081-1090. [PubMed: 14642968]

Kapur S, Remington G. Dopamine D(2) receptors and their role in atypical antipsychotic action: still necessary and may even be sufficient. Biol. Psychiatry. 2001; 50(11):873-883. [PubMed: 11743942] 
Kapur S, Remington G, Zipursky RB, Wilson AA, Houle S. The D2 dopamine receptor occupancy of risperidone and its relationship to extrapyramidal symptoms: a PET study. Life Sci. 1995; 57(10):PL103-107. [PubMed: 7543969]

Kapur S, Seeman P. Does fast dissociation from the dopamine d(2) receptor explain the action of atypical antipsychotics?: A new hypothesis. Am. J. Psychiatry. 2001; 158(3):360-369. [PubMed: 11229973]

Kapur S, Zipursky R, Jones C, Remington G, Houle S. Relationship between dopamine D(2) occupancy, clinical response, and side effects: a double-blind PET study of first-episode schizophrenia. Am. J. Psychiatry. 2000; 157(4):514-520. [PubMed: 10739409]

Kontny NE, Wurthwein G, Joachim B, Boddy AV, Krischke M, Fuhr U, Thompson PA, Jorger M, Schellens JH, Hempel G. Population pharmacokinetics of doxorubicin: establishment of a NONMEM model for adults and children older than 3 years. Cancer Chemother Pharmacol. 2013; 71(3):749-763. [PubMed: 23314734]

Margolese HC, Chouinard G, Kolivakis TT, Beauclair L, Miller R. Tardive dyskinesia in the era of typical and atypical antipsychotics. Part 1: pathophysiology and mechanisms of induction. Can. J. Psychiatry. 2005; 50(9):541-547. [PubMed: 16262110]

Marsot A, Boulamery A, Bruguerolle B, Simon N. Vancomycin: a review of population pharmacokinetic analyses. Clin Pharmacokinet. 2012; 51(1):1-13. [PubMed: 22149255]

Miller DD, McEvoy JP, Davis SM, Caroff SN, Saltz BL, Chakos MH, Swartz MS, Keefe RS, Rosenheck RA, Stroup TS, Lieberman JA. Clinical correlates of tardive dyskinesia in schizophrenia: baseline data from the CATIE schizophrenia trial. Schizophr Res. 2005; 80(1):3343. [PubMed: 16171976]

Mizuno Y, Bies RR, Remington G, Mamo DC, Suzuki T, Pollock BG, Tsuboi T, Watanabe K, Mimura M, Uchida H. Dopamine D2 receptor occupancy with risperidone or olanzapine during maintenance treatment of schizophrenia: A cross-sectional study. Prog. Neuropsychopharmacol. Biol. Psychiatry. 2011; 37(1):182-187. [PubMed: 22230651]

Moriguchi S, Bies RR, Remington G, Suzuki T, Mamo DC, Watanabe K, Mimura M, Pollock BG, Uchida H. Estimated Dopamine D2 Receptor Occupancy and Remission in Schizophrenia: Analysis of the CATIE Data. J. Clin. Psychopharmacol. 2013; 33(5):682-685. [PubMed: 23899638]

Oosthuizen PP, Emsley RA, Maritz JS, Turner JA, Keyter N. Incidence of tardive dyskinesia in firstepisode psychosis patients treated with low-dose haloperidol. J. Clin. Psychiatry. 2003; 64(9): 1075-1080. [PubMed: 14628983]

Remington G. Tardive dyskinesia: eliminated, forgotten, or overshadowed? Curr Opin. Psychiatry. 2007; 20(2):131-137. [PubMed: 17278910]

Remington G, Seeman P, Feingold A, Mann S, Shammi C, Kapur S. "Extended" antipsychotic dosing in the maintenance treatment of schizophrenia: a double-blind, placebo-controlled trial. J. Clin. Psychiatry. 2011; 72(8):1042-1048. [PubMed: 20868639]

Samaha AN, Reckless GE, Seeman P, Diwan M, Nobrega JN, Kapur S. Less is more: antipsychotic drug effects are greater with transient rather than continuous delivery. Biol. Psychiatry. 2008; 64(2):145-152. [PubMed: 18295747]

Samaha AN, Seeman P, Stewart J, Rajabi H, Kapur S. "Breakthrough" dopamine supersensitivity during ongoing antipsychotic treatment leads to treatment failure over time. J. Neurosci. 2007; 27(11):2979-2986. [PubMed: 17360921]

Sheiner LB, Rosenberg B, Marathe VV. Estimation of population characteristics of pharmacokinetic parameters from routine clinical data. J. Pharmacokinet. Biopharm. 1977; 5(5):445-479. [PubMed: 925881]

Soares-Weiser K, Fernandez HH. Tardive dyskinesia. Semin. Neurol. 2007; 27(2):159-169. [PubMed: 17390261]

Stroup TS, McEvoy JP, Swartz MS, Byerly MJ, Glick ID, Canive JM, McGee MF, Simpson GM, Stevens MC, Lieberman JA. The National Institute of Mental Health Clinical Antipsychotic Trials of Intervention Effectiveness (CATIE) project: schizophrenia trial design and protocol development. Schizophr. Bull. 2003; 29(1):15-31. [PubMed: 12908658] 
Tenback DE, van Harten PN. Epidemiology and risk factors for (tardive) dyskinesia. Int. Rev. Neurobiol. 2011; 98:211-230. [PubMed: 21907089]

Tenback DE, van Harten PN, van Os J. Non-therapeutic risk factors for onset of tardive dyskinesia in schizophrenia: a meta-analysis. Mov. Disord. 2009; 24(16):2309-2315. [PubMed: 19645070]

Tenback DE, van Harten PN, Slooff CJ, Belger MA, van Os J. Effects of antipsychotic treatment on tardive dyskinesia: a 6-month evaluation of patients from the European Schizophrenia Outpatient Health Outcomes (SOHO) Study. J. Clin. Psychiatry. 2005; 66(9):1130-1133. [PubMed: 16187770]

Tollefson GD, Beasley CM Jr. Tamura RN, Tran PV, Potvin JH. Blind, controlled, long-term study of the comparative incidence of treatment-emergent tardive dyskinesia with olanzapine or haloperidol. Am. J. Psychiatry. 1997; 154(9):1248-1254. [PubMed: 9286184]

Turrone P, Remington G, Kapur S, Nobrega JN. The relationship between dopamine D2 receptor occupancy and the vacuous chewing movement syndrome in rats. Psychopharmacology (Berl). 2003; 165(2):166-171. [PubMed: 12417967]

Turrone P, Remington G, Kapur S, Nobrega JN. Continuous but not intermittent olanzapine infusion induces vacuous chewing movements in rats. Biol. Psychiatry. 2005; 57(4):406-411. [PubMed: 15705357]

Uchida H, Kapur S, Mulsant BH, Graff-Guerrero A, Pollock BG, Mamo DC. Sensitivity of older patients to antipsychotic motor side effects: a PET study examining potential mechanisms. Am. J. Geriatr. Psychiatry. 2009a; 17(3):255-263. [PubMed: 19225277]

Uchida H, Mamo DC. Dosing of antipsychotics in schizophrenia across the life-spectrum. Prog. Neuropsychopharmacol. Biol. Psychiatry. 2009; 33(6):917-920. [PubMed: 19426777]

Uchida H, Mamo DC, Pollock BG, Suzuki T, Tsunoda K, Watanabe K, Mimura M, Bies RR. Predicting plasma concentration of risperidone associated with dosage change: a population pharmacokinetic study. Ther. Drug Monit. 2012; 34(2):182-187. [PubMed: 22377743]

Uchida H, Pollock BG, Bies RR, Mamo DC. Predicting age-specific dosing of antipsychotics. Clin. Pharmacol. Ther. 2009b; 86(4):360-362. [PubMed: 19763115]

Uchida H, Suzuki T, Takeuchi H, Arenovich T, Mamo DC. Low dose vs standard dose of antipsychotics for relapse prevention in schizophrenia: meta-analysis. Schizophr. Bull. 2011a; 37(4):788-799. [PubMed: 19946012]

Uchida H, Takeuchi H, Graff-Guerrero A, Suzuki T, Watanabe K, Mamo DC. Predicting dopamine $\mathrm{D}(2)$ receptor occupancy from plasma levels of antipsychotic drugs: a systematic review and pooled analysis. J. Clin. Psychopharmacol. 2011b; 31(3):318-325. [PubMed: 21508857]

van Harten PN, Tenback DE. Tardive dyskinesia: clinical presentation and treatment. Int. Rev. Neurobiol. 2011; 98:187-210. [PubMed: 21907088]

Wessels AM, Bies RR, Pollock BG, Schneider LS, Lieberman JA, Stroup S, Li CH, Coley K, Kirshner MM, Marder SR. Population pharmacokinetic modeling of ziprasidone in patients with schizophrenia from the CATIE study. J. Clin. Pharmacol. 2011; 51(11):1587-1591. [PubMed: 21209243]

WHO. [December 11, 2013] Collaborating Centre for Drug Statistics Methodology. 2013. Available at: http://www.whocc.no/atcddd/.

Woods SW, Morgenstern H, Saksa JR, Walsh BC, Sullivan MC, Money R, Hawkins KA, Gueorguieva $\mathrm{RV}$, Glazer WM. Incidence of tardive dyskinesia with atypical versus conventional antipsychotic medications: a prospective cohort study. J. Clin. Psychiatry. 2010; 71(4):463-474. [PubMed: 20156410] 
Table 1

Demographic and Clinical Characteristics of the Subjects $(\mathrm{N}=218)$.

\begin{tabular}{lr}
\hline Characteristics & \\
\hline Age, years, mean \pm SD (range) & \\
Sex & $167(76.6 \%)$ \\
$\quad$ Male, N (\%) & $51(23.4 \%)$ \\
Female, N (\%) & \\
Race & $127(58.3 \%)$ \\
Caucasian, N (\%) & $82(37.6 \%)$ \\
African-American, N (\%) & $2(0.9 \%)$ \\
Native American, N (\%) & $5(2.3 \%)$ \\
Asian, N (\%) & $1(0.5 \%)$ \\
Mixed, N (\%) & $1(0.5 \%)$ \\
Missing value, N (\%) & \\
Medication & $78(35.8 \%)$ \\
Risperidone, N (\%) & $100(45.9 \%)$ \\
Olanzapine, N (\%) & $40(18.4 \%)$ \\
Ziprasidone, N (\%) & $14.5 \pm 4.5$ \\
Years since first prescribed an AP \pm SD (range) & $11.6 \pm 9.9(0-44)$ \\
Duration of study participation $\pm \mathrm{SD}($ month) &
\end{tabular}

Abbreviations: AP, antipsychotic; SD, standard variation 


\section{Table 2}

Association between clinical demographics, estimated dopamine D2 receptor occupancy and the emergence of tardive dyskinesia

\begin{tabular}{|c|c|c|c|}
\hline Variables & Odds Ratio & $95 \% \mathrm{CI}$ & p-value \\
\hline \multicolumn{4}{|l|}{ Sex } \\
\hline Male & 1 (reference) & & \\
\hline Female & 1.45 & $0.52-4.03$ & 0.47 \\
\hline \multicolumn{4}{|l|}{ Age (years) } \\
\hline$<50$ & 1 (reference) & & \\
\hline 250 & 1.86 & $0.50-6.92$ & 0.35 \\
\hline \multicolumn{4}{|l|}{ Race } \\
\hline Caucasian & 1 (reference) & & \\
\hline African-American & 1.49 & $0.55-4.03$ & 0.42 \\
\hline Native American & 0 & & 0.99 \\
\hline Asian & 2.57 & $0.22-30.1$ & 0.45 \\
\hline Mixed & 0 & & 1 \\
\hline \multicolumn{4}{|l|}{ Antipsychotic } \\
\hline Risperidone & 1 (reference) & & \\
\hline Olanzapine & 1.02 & $0.37-2.80$ & 0.96 \\
\hline Ziprasidone & 2.94 & $0.38-22.56$ & 0.29 \\
\hline Estimated D2 Occupancy at Peak & 0.95 & $0.80-1.13$ & 0.59 \\
\hline Estimated D2 Occupancy at Trough & 1.07 & $0.95-1.21$ & 0.23 \\
\hline Years since first prescribed an AP & 1.06 & $0.95-1.05$ & 0.80 \\
\hline Duration of study participation & 0.95 & $0.86-1.06$ & 0.40 \\
\hline
\end{tabular}

